\title{
DINÂMICA DA EXPANSÃO AGRÍCOLA DO MUNICÍPIO DE SÃO DESIDÉRIO-BA ENTRE OS ANOS DE 1984 A 2008, IMPORTANTE PRODUTOR NACIONAL DE SOJA, ALGODÃO E MILHO
}

\author{
AGRICULTURAL EXPANSION DYNAMICS OF THE SÃO \\ DESIDÉRIO-BA MUNICIPALITY FROM 1984 TO 2008, \\ IMPORTANT NATIONAL PRODUCER OF SOYBEAN, COTTON \\ AND CORN
}

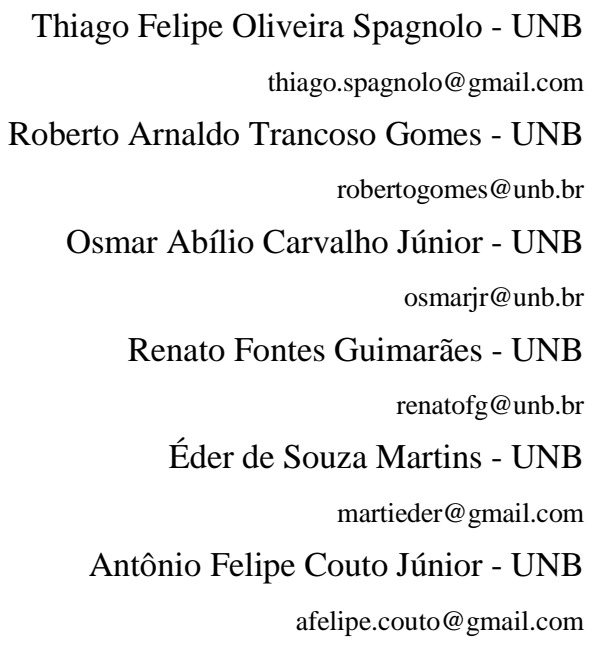

\section{RESUMO}

O presente trabalho possui como objetivo analisar a dinâmica da expansão agrícola no município de São Desidério entre os anos de 1984 e 2008, localizado na mesoregião do Extemo Oeste da Bahia. No estudo da dinâmica da expansão agrícola foi utilizada uma série temporal de imagens dos sensores PRISM/ALOS e TM-Landsat. As imagens foram co-registradas e classificadas por interpretação visual para obtenção de uma melhor precisão das classes de uso e cobertura da terra. As interpretações foram validadas com trabalho de campo. As classes de uso e cobertura da terra foram quantificadas e analisadas ao longo do tempo. Na detecção de mudança foi utilizada a técnica de pós-classificação. Como resultado foi constatado que a área de agricultura teve um significativo aumento sendo de 4\% do município em 1984 e 32,5\% em 2008, crescendo a uma taxa média de 17.605 hectares por ano. A agricultura irrigada por pivôs-centrais também mostrou um crescimento significativo no período analisado. Esta prática de cultivo não era encontrada no município em 1984, porém, até 2008 já tinham sido implementados 254 pivôs. 
Palavras-chave:Detecção de Mudança. Geografia Agrária. Agricultura. Uso da Terra. SensoriamentoRemoto.

\begin{abstract}
This paper aims to analyze the agricultural expansion in the São Desidério municipality,located in the region of Western Bahia, in the period 1984 to 2008. Time series images from sensors PRISM/ALOS and Landsat-TM was used in the description of agricultural expansion. The images were co-registered and classified by visual interpretation in order to obtain better accuracy of the land-use and land-cover classes.Image interpretations were validated with field-works. The classes were quantified and analyzed over time.Thepost-classification method was used to change detection.The agricultural area increased significantly, with $4 \%$ of the municipality in 1984 and $32.5 \%$ in 2008, growing an average rate of 17,605 hectares per year. Center pivot irrigation has also shown significant growth over the period analyzed, from none in 1984 to 254 in 2008.
\end{abstract}

Keywords: Change Detection. Agricultural Geography.Agriculture. Land Use.Remote Sensing.

\title{
INTRODUÇÃO
}

O Cerrado brasileiro é uma região biogeográfica de extrema riqueza sociocultural e ecológica, destacando-se como área importante para a conservação da biodiversidade (KLINK \& MOREIRA, 2002). No entanto, nos últimos trinta anos tornou-se uma das principais fronteiras agrícolas devido à expansão do agronegócio global, e em 2008 cerca de $40 \%$ da vegetação natural do Bioma Cerrado já tinha sido convertida em agropecuária e outros tipos de uso (BRANNSTROMet al., 2008; MAZZETO SILVA, 2009; SANO et al., 2008). A modernização tecnológica, estimulada pelas políticas comerciais e agrícolas, gerou ganho de produtividade neste bioma. As frentes de agricultura em áreas de Cerrado significaram a implantação de um sistema de produção intensivo, utilizado principalmente na cultura da soja, do milho, e posteriormente do algodão herbáceo (GUIMARÃES \& LEME, 1997).

Dentro do ambiente de Cerrado uma das principais fronteiras agrícolas é o Oeste da Bahia que desde a década de 1980, vem se consolidando como um dos principais pólos de produção de grãos do Cerrado (BRANNSTROMet al., 2008; SANO \& PINHATI, 2009; MENDONÇA, 2006). No processo de ocupação agrícola do Oeste-Baiano, a política pública de subsidiar compras de terras a preços e juros reduzidos (Klink \& Moreira, 2002) e, as forças econômicas e políticas regionalmente dominantes têm desempenhado papel importante como facilitadores para os produtores, vindos 
principalmente das regiões Sul e Sudeste (GUIMARÃES \& LEME, 1997). O apoio do governo foi importante para ajudar na implantação do novo modelo agrícola na região, voltado para o agronegócio (KLINK \& MOREIRA, 2002). Dessa forma, o Oeste da Bahia, com extensas áreas de Cerrado nativo no início da década de 1980, antes consideradas como espaços "vazios" e "marginais" do Estado (SANTOS, 2008), em 2007 passa a contribuir com 49\% da área total ocupada com culturas anuais na Bahia (IBGE, 2010).

O presente trabalho possui como objetivo analisar a dinâmica da expansão agrícola no Município de São Desidério entre os anos 1984 e 2008 utilizando técnicas de sensoriamento remoto e trabalho em campo.

\section{ÁREA DE ESTUDO}

A área de estudo é o município de São Desidério (Mapa 1), abrangendo 12,7\% da Mesorregião Extremo Oeste Baiano. Este município possui uma população estimada de 27.513 habitantes, com uma população rural e urbana, respectivamente, de $63 \%$ e $37 \%$, em uma área de $14.820 \mathrm{~km}^{2}$, e apresenta uma densidade demográfica $1,86 \mathrm{hab} / \mathrm{km}^{2}$ (IBGE, 2010).

O Oeste da Bahiaapresenta estações bem definidas, com precipitação média anual de $1500 \mathrm{~mm}$, concentrada na estação chuvosa de outubro a abril. A precipitação mostra uma variação de acordo com a altimetria, sendo maior nas áreas mais altas (Topo) com $1600 \mathrm{~mm}$ e a $100 \mathrm{~km}$ para leste nas áreas mais baixas com $1400 \mathrm{~mm}$ (BRANNSTROMet al., 2008). Esta característica estabelece uma diferença climática sendo úmida na parte oeste e subúmido seco na parte leste (SEI, 1997). A temperatura média anual apresenta amplitude de $21,3^{\circ}$ a $27,2^{\circ} \mathrm{C}$.

O município contém dois grupos geológicos Urucuia e Bambuí. O Grupo Urucuia(Cretáceo) constituído quase que exclusivamente por arenitos de origem eólica. O Grupo Bambuí (Neoproterozóico) evidencia rochas calcárias e pelíticas, depositadas sobre rochas do embasamento cristalino relativos ao Cráton do São Francisco, sendo encontrados nesta região os solos de maior fertilidade (GASPAR \& CAMPOS, 2007). 

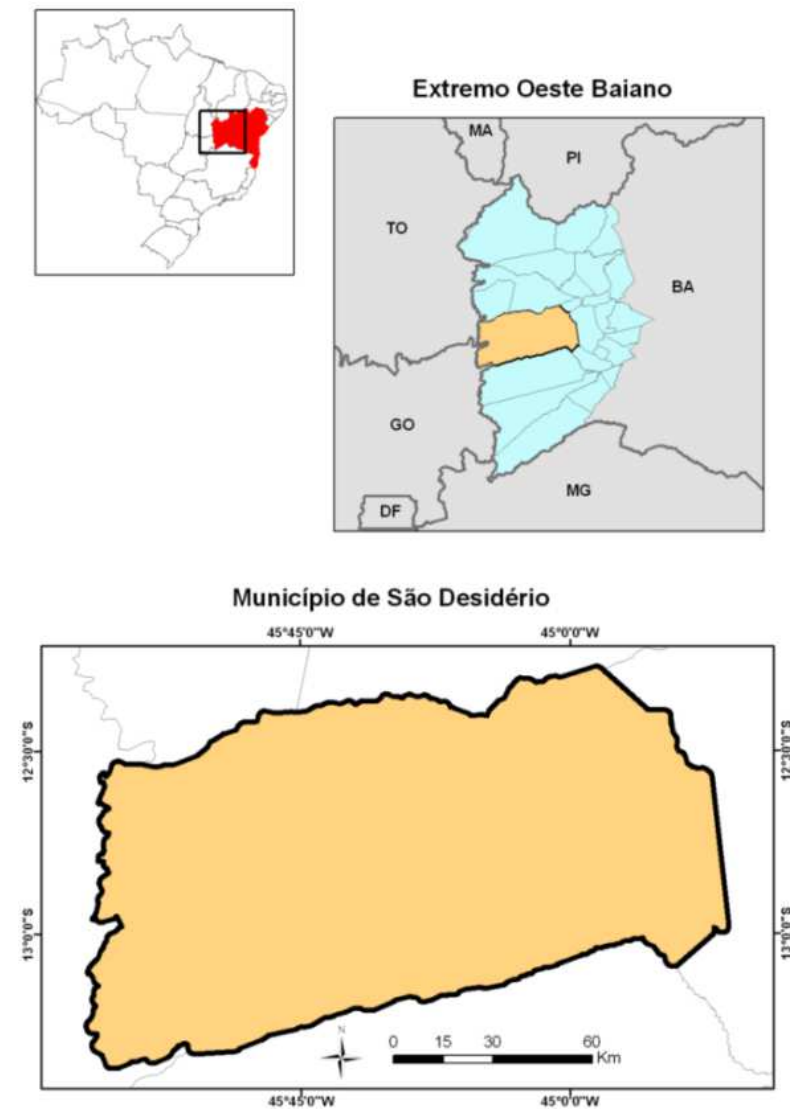

Mapa 1- Localização do Município de São Desidério na Mesorregião Extremo Oeste Baiano.

Os solos são bem intemperizados e com baixa fertilidade natural, geralmente bem drenado e com baixa capacidade de retenção de água (SANTOS et al., 2008). Ocorrem em maior concentração os Latossolos Vermelhos e Vermelho-Amarelos e os NeossolosQuartzarênicos, nas áreas de vales e veredas há a ocorrência de Gleissolos e Organossolos, compondo as planícies estão Latossolos, Argissolos, NeossolosQuartzarênicos, Luvissolos e Planossolos e nas regiões de encosta são encontrados os NeossolosLitólicos (BATISTELLA et al., 2002).

$\mathrm{Na}$ área encontram-se quatro regiões fitoecológicas distintas: Cerrado Sensu Strictu, Floresta de Galeria/Veredas/Campo úmido, Ecótono Caatinga Arbórea/Cerrado e Floresta Submontana. As Chapadas estão associadas à presença das coberturas vegetais típicas de savana que não ocorrem, por exemplo, nos fundos de vale, onde aparecem as matas de galeria, veredas e brejos (MAZZETO SILVA, 2009).

\section{MATERIAL E MÉTODOS}

\section{Imagens ALOS-PRISM e TM-Landsat}

Geo UERJ - Ano 14, no. 23,v. 2, $2^{\circ}$ semestre de 2012 p. 603-618

ISSN: $1415-7543$ E-ISSN: 1981-9021

http://www.e-publicacoes.uerj.br/index.php/geouerj 
No estudo da dinâmica de uso do solo foram utilizadas imagens de alta resolução espacial do ano de 2008 relativas ao sensor Panchromatic Remote-SensingInstrument for StereoMapping (PRISM) e uma série temporal advinda do sensor Landsat/TM referente aos anos de 1984, 1988, 1992, 1996, 2000, 2004 e 2008.

O sensor PRISM está a bordo do satélite Advanced Land ObservingSatellite (ALOS) desenvolvido pela JapanAerospaceExplorationAgency (JAXA) lançado em 2006,possui órbita circular heliossíncrona, altitude de $692 \mathrm{~km}$ e resolução temporal de 46 dias (IGARASHI, 2001). O sensor PRISM é composto por um conjunto de 3 sistemas de aquisição de imagem, denominado Triplet, que obtém de forma simultânea imagens com visadas nadir, inclinada para frente e inclinada para trás, o que torna possível a aquisição de imagens estereoscópicas ao longo da trajetória e a construção do modelo digital de terreno. A largura da faixa de imageamento é de $35 \mathrm{~km}$ no modo de observação estéreo e de $70 \mathrm{~km}$ em observação nadir (TADONOet al., 2004). No presente trabalho foram utilizadas as imagens pancromáticas de 8 bits do sensor PRISM com resolução espacial de 2,5 m, referentes ao produto $1 \mathrm{~B} 2$, que são submetidas à calibração radiométrica e geométrica, com os pixels alinhados com a grade da projeção UTM.

As imagens do sensor multiespectral LandsatThematicMapper (TM) é um dos mais difundido no mundo e apresenta uma das melhores relações entre custo e benefício dentre os dados gerados a partir de satélites de média resolução (15 a 30 metros). Cada cena do Landsat cobre uma área no terreno de $185 \mathrm{~km}$ x $185 \mathrm{~km}$.

\section{Processamento das Imagens Temporais}

Neste trabalho as imagens TM foram inicialmente co-registradas utilizando as imagens do sensor ALOS/PRISM, visando uma sobreposição precisa para a realização da análise multitemporal.A classificação das imagens foi feita por interpretação visual em tela, inicialmente das imagens do sensor PRISM referente ao ano de 2008, e posteriormentecom a série temporal do sensor Landsat (1984, 1988, 1992, 1996, 2000, 2004 e 2008). A interpretação visual foi utilizada, em detrimento de métodos automatizados, pois muitas das diferenças nos valores de reflectância das imagens não possuem um significado para a classificação desejada. Isto significa que uma área de agricultura pode apresentar diversos estágios, por exemplo: solo exposto, vegetação 
verde densa ou vegetação seca. Estas variações podem ocasionar diferentes valores de reflectância para um mesmo tipo de uso da terra, o que gerava erros nos métodos automatizados. A interpretação visual foi realizada com base nos elementos de interpretação da imagem como: tonalidade/cor, textura (rugosidade), forma, padrão (arranjo espacial dos objetos), localização e contexto, além de observações obtidas em campo. Essa combinação de elementos permitiu a delimitação precisa e correta de cada classe de uso (FLORENZANO, 2008).

As classes mapeadas de uso e cobertura do solo foram: (1) Vegetação Natural, áreas ainda não alteradas por intervenção antrópica, ou já regeneradas após alteração; (2) Área Urbana; (3) Agricultura, caracterizada por agricultura de sequeiro, altamente mecanizada, tendo como principais culturas a soja, o milho e o algodão; (4) Pivô Central, áreas irrigadas por meio de pivô-central; (5) Reflorestamento, plantios de Eucalipto; (6) Massa d'água, representando os cursos d'água, áreas alagadas e represas; (7) Lagoa Cárstica; (8) Uso Múltiplo, caracterizada por pequenas propriedades, onde são desenvolvidas diversas atividades agrícolas (mandioca, banana, manga, coco, capins para ração de gado, pequenos pastos, entre outros), além de pecuária; (9) Uso Indefinido, áreas de solo exposto que não puderam ser classificadas devido à resolução espacial das imagens TM; e (10) Vegetação Alterada, áreas que foram desmatadas. A classe de área urbana é representada por três áreas, que juntas somam apenas 0,02\% da área total do Município: cidade de São Desidério, Roda Velha e Povoado Sítio Grande.

Na detecção de mudança foi utilizado o método de pós-classificação (MAS, 1999; DE BRUIN, 2000; MUNYATI, 2000). Neste procedimento as imagens são classificadas separadamente e posteriormente comparadas entre si, buscando quantificar as áreas onde ocorreu mudança no uso e cobertura do solo. As principais vantagens desta técnica são (COPPIN et al., 2004; MENKE et al., 2009): (a) fácil atualização ao longo do tempo favorecendo o monitoramento; (b) permitir compensar as variações provenientes das condições atmosféricas, mudanças fenológicas e umidade de solo, devido à independência na confecção do mapa temático; e (c) permitir integrar e comparar imagens de sensores com diferentes resoluções espaciais, espectrais, temporais e radiométricas. A quantificação das mudanças foi considerada para cada tipo de uso e cobertura ao longo da série temporal (1984 e 2008), permitindo detalhar a dinâmica espacial de ocupação.

Geo UERJ - Ano 14, no. 23,v. 2, $2^{\circ}$ semestre de 2012 p. 603-618

ISSN: $1415-7543$ E-ISSN: 1981-9021

http://www.e-publicacoes.uerj.br/index.php/geouerj 


\section{RESULTADOS E DISCUSSÕES}

\section{Análise Multitemporal doUso e Cobertura do Solo entre 1984 e 2008}

A partir da análise da imagem ALOS do ano de 2008,observa-se que a Vegetação Natural $(57,19 \%)$ e a Agricultura (32,54\%) ocuparam juntas aproximadamente $90 \%$ da área do Município (Mapa 2). A vegetação alterada ocupou uma área de 5,47\%, seguida do Uso Múltiplo com 2,72\%, Pivô Central com 1,71\% e Reflorestamento com 0,18\%. As demais classes ocuparam áreas pequenas, tornando-se pouco expressiva quando comparadas às classes maiores.

$\mathrm{Na}$ dinâmica de ocupação destaca-se o crescimento da agricultura voltada para o agronegócio em detrimento da vegetação natural (Mapa 3). O padrão espacial do avanço da agricultura ocorre de Oeste para Leste, com conversão de extensas áreas de vegetação natural em curto período de tempo. A ocupação transcorreu preferencialmente nas áreas mais altas e planas a oeste, onde a distribuição sazonal e a quantidade de precipitação pluvial anual são adequadas para a agricultura de sequeiro. Estas condições possibilitaram a consolidação da agricultura mecanizada nesta região, principalmente para a produção de grãos como soja e milho, além de algodão herbáceo (GASQUES et al., 2004).

Considerando apenas as feições de detecção de mudança entre o intervalo de quatro anos (Mapa 4) torna-se evidente a tendência de expansão agrícola. Primeiramente a agricultura ocupou as áreas a oeste e em seguida se expandiu em direção a porção central do município e por fim a parte leste. 


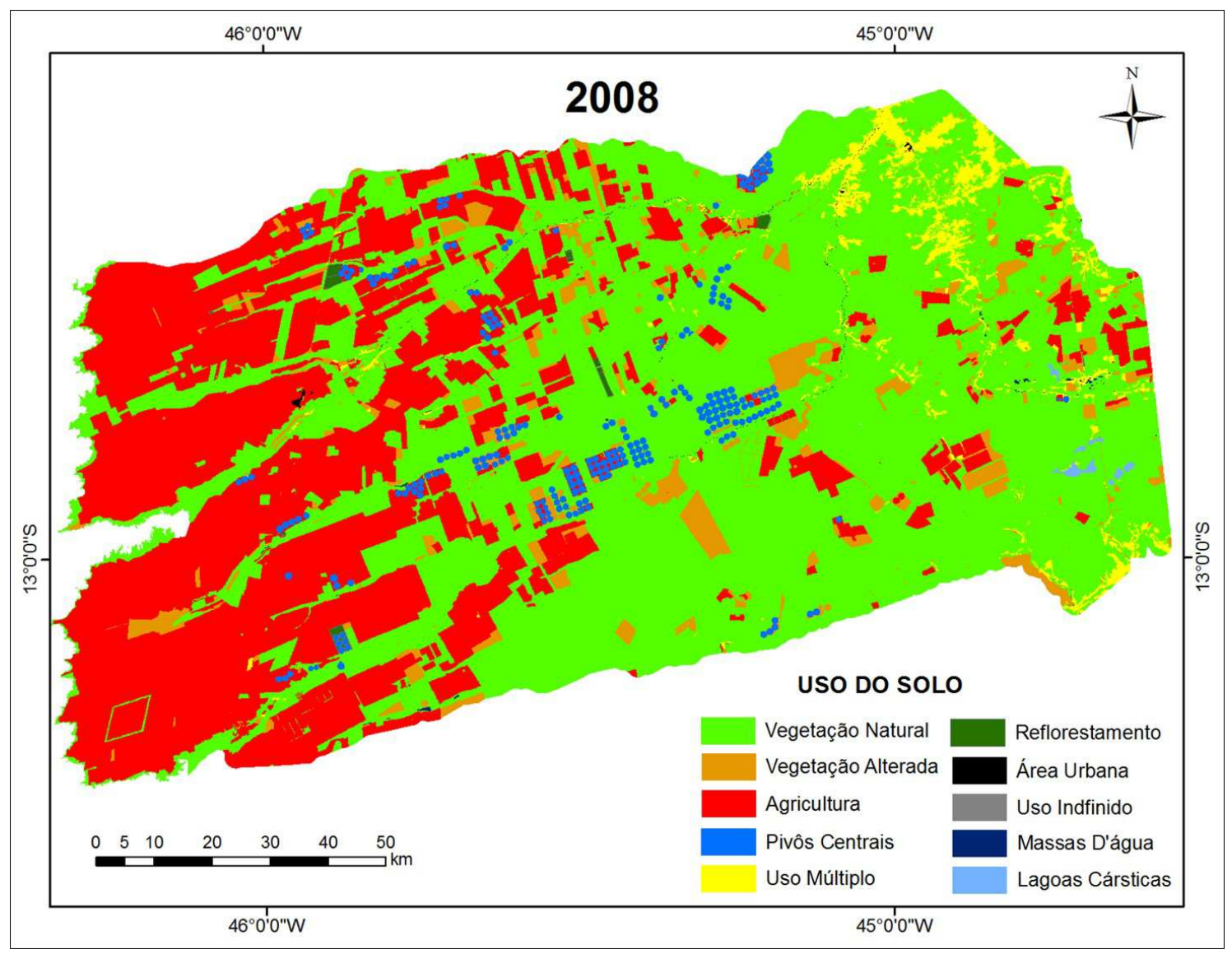

Mapa 2- Uso e cobertura da Terra do município de São Desidério relativa ao ano de 2008.

Desta forma, a área ocupada com agricultura de sequeiro apresentou um crescimento constante e considerável entre 1984 e 2008, passando de 4\% para 32,5\% (Tabela 1). Torna-se evidente que o município desenvolveu-se economicamente a partir da década de 1980, com a expansão do agronegócio. Em 2008 a agricultura de sequeiro ocupava uma área de 481.650 ha no Município de São Desidério. Esses resultados confirmam os dados do IBGE de Produção Municipal para Culturas Temporárias (2008), onde consta uma área colhida de 471.000 ha. No ano de 2008, o Produto Interno Bruto (PIB) da agropecuária no município foi o maior do estado da Bahia contribuindo com mais de $\mathrm{R} \$$ 753 milhões. 


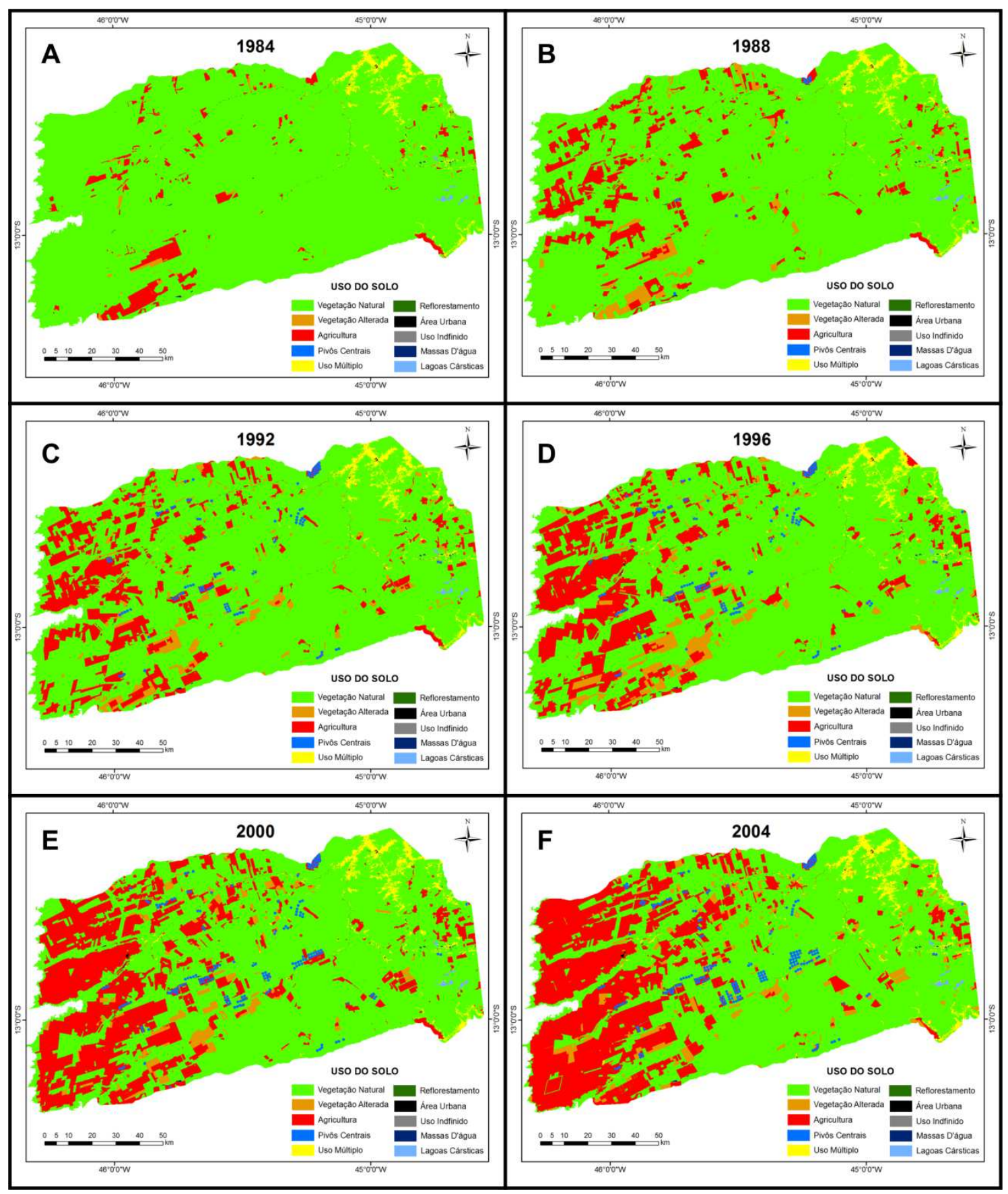

Mapa 3- Evolução temporal do uso e cobertura do solo no município de São Desidério: (a) 1984, (b) 1988, (c) 1992, (d) 1996, (e) 2000 e (f) 2004.

Três tipos de culturas destacam-se em relação ao total de área plantada com culturas temporárias: soja (54\%), algodão (29\%) e milho (11\%), que somam 94\% (IBGE, 2010). Em 1991 a produção de soja representava 0,462\% da produção nacional, que passou a representar 1,307\% em 2008 (774.180 Toneladas, em área colhida de 255.000 ha) 
(IBGE - Produção Agrícola Municipal). O município torna-se o maior produtor de soja e milho do Norte/Nordeste (IBGE, 2010).

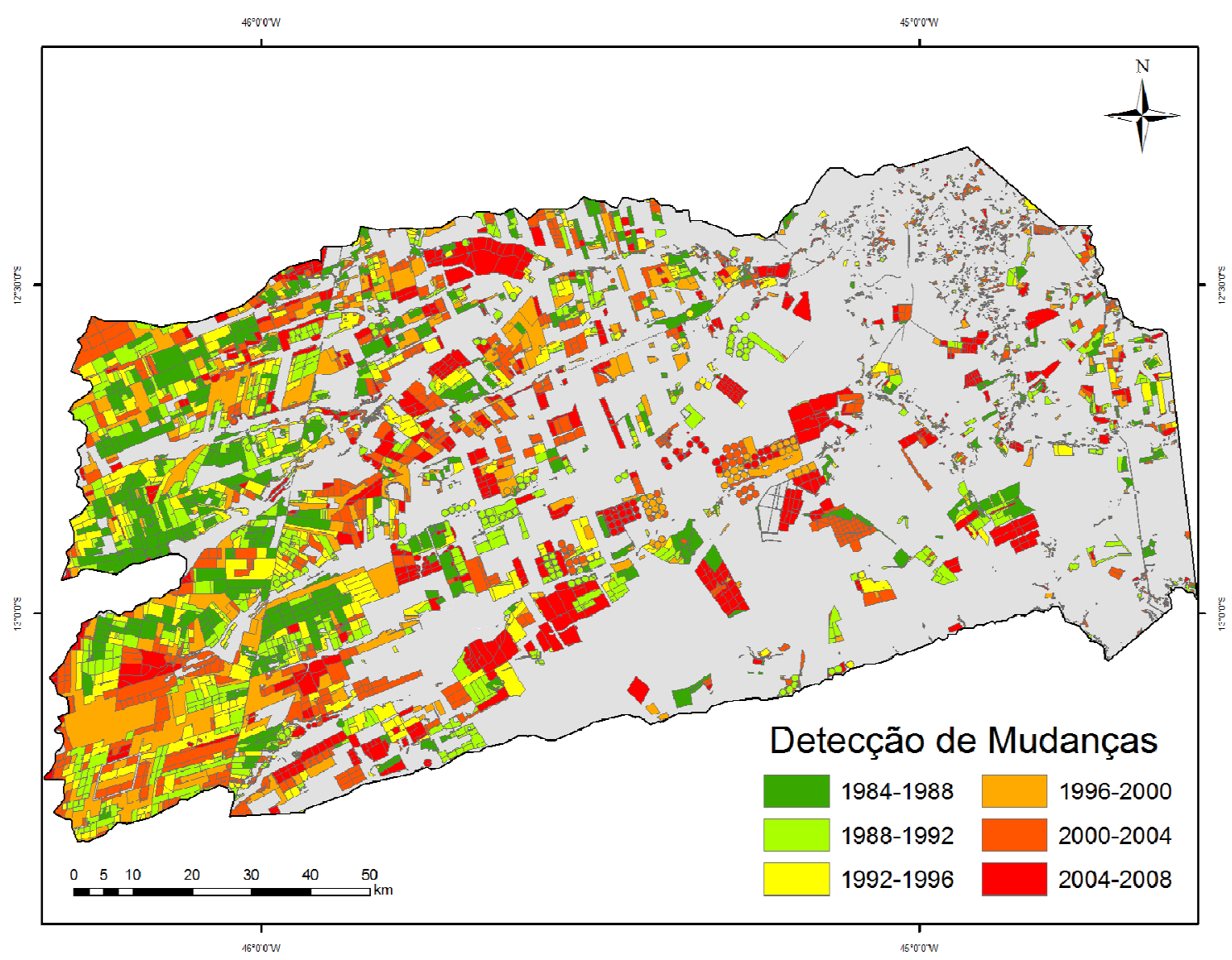

Mapa 4- Detecção de mudança no intervalo de quatro anos referente à implantação do uso da terra em áreas de vegetação natural no município de São Desidério.

Tabela 1 - Valores percentuais referentes às áreas ocupadas por cada classe ao longo do tempo.

\begin{tabular}{llllllll}
\hline USO & $\mathbf{1 9 8 4}$ & $\mathbf{1 9 8 8}$ & $\mathbf{1 9 9 2}$ & $\mathbf{1 9 9 6}$ & $\mathbf{2 0 0 0}$ & $\mathbf{2 0 0 4}$ & $\mathbf{2 0 0 8}$ \\
\hline Área Urbana & 0,01 & 0,01 & 0,01 & 0,01 & 0,02 & 0,02 & 0,02 \\
Uso Indefinido & 0,00 & 0,00 & 0,01 & 0,01 & 0,02 & 0,01 & 0,02 \\
\hline Vegetação Alterada & 0,68 & 3,10 & 3,76 & 5,23 & 3,11 & 4,49 & 5,47 \\
Agricultura & 3,99 & 8,85 & 13,32 & 17,21 & 24,64 & 27,69 & 32,50 \\
Massa d'água & 0,08 & 0,08 & 0,08 & 0,08 & 0,08 & 0,08 & 0,08 \\
Lagoa Cárstica & 0,12 & 0,12 & 0,12 & 0,12 & 0,12 & 0,12 & 0,12 \\
Uso Múltiplo & 1,69 & 1,72 & 1,82 & 2,03 & 2,22 & 2,51 & 2,72 \\
Pivô Central & 0,00 & 0,08 & 0,73 & 0,96 & 1,16 & 1,37 & 1,71 \\
Reflorestamento & 0,00 & 0,00 & 0,00 & 0,00 & 0,01 & 0,01 & 0,18 \\
Vegetação Natural & 93,43 & 86,05 & 80,15 & 74,34 & 68,62 & 63,71 & 57,19 \\
\hline TOTAL & 100,00 & 100,00 & 100,00 & 100,00 & 100,00 & 100,00 & 100,00 \\
\hline FOnte: Autores
\end{tabular}

Fonte: Autores

Houve também um crescimento expressivo da produção de algodão, em que no ano de 1991 a produção era baixa, representando 0,005\% da produção nacional, e passou em 
2008 a representar 13,415\% (534.342 Toneladas, em área colhida de 136.756 ha). Este rápido crescimento das áreas plantadas com algodão mostra os resultados do programa PROALBA, criado em 2001, com o objetivo de apoiar os empreendimentos ligados à cadeia do agronegócio do algodão. Desta forma, o município de São Desidério se tornou o maior produtor de algodão do Brasil.

Entre 1984 e 2008, a Vegetação Natural teve uma redução de 36\% (537.077 ha) contrapondo com a Agricultura que teve um incremento de quase 30\%, Vegetação Alterada $5 \%$ e Pivôs-Centrais de $1,7 \%$ (Gráfico 1). O emprego do diagrama de dispersão contrapondo a porcentagem da área vegetação natural e de agricultura dentro do município descreve um comportamento linear inverso entre essas duas variáveis. Este fato demonstra que o crescimento da agricultura foi durante todo o período constante considerando uma relação entre vegetação natural em relação à agricultura de -1,2, demonstrado pelo coeficiente angular da função linear (Gráfico 2). Este fato demonstra que o processo de expansão agrícola ainda não estabilizou e continua em expansão diferentemente do município de Luis Eduardo Guimarães que demonstra uma tendência de diminuição do processo de expansão nos últimos anos (MENKEet al., 2009). A taxa média de conversão da Vegetação Natural foi de 22.378 hectares ao ano, enquanto a taxa de crescimento da agricultura foi de 17.605 (Tabela 2).

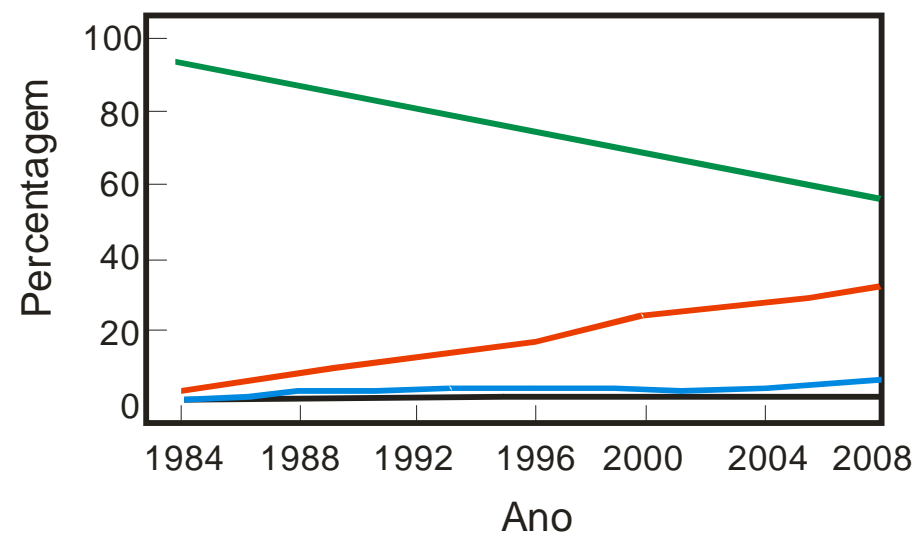

Gráfico 1- Percentual ocupado pelas principais classes de uso ao longo do tempo: (a) vegetação natural (verde), agricultura (vermelho), vegetação alterada (azul), uso múltiplo (preto). 
A agricultura irrigada por pivôs-centrais mostrou crescimento significativo no período analisado. Em 1984 o município não apresentava nenhum pivô central, evoluindo para 254 pivôs em 2008 (Gráfico 3), que corresponde a uma área de 27.190 hectares. Esse tipo de uso ocorre ao longo das drenagens, pois utiliza a água dos rios, nascentes, ou do lençol freático. Cada pivô central ocupa uma área média de 107 ha, sendo utilizado principalmente para produção de soja, milho, feijão e café. Este aumento demonstra o investimento em tecnologia e aprimoramento na produção.

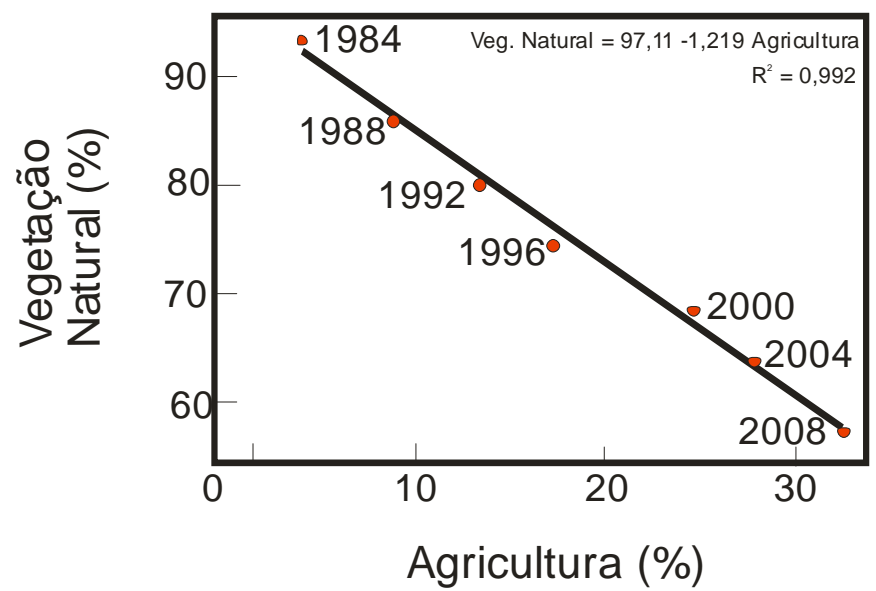

Gráfico 2- Relação inversamente proporcional entre Agricultura e Vegetação Natural no período de 1984 a 2008.

Tabela 2 - Taxas de conversão da Vegetação Natural e Crescimento da Agricultura (ha.ano ${ }^{-1}$ ) ao longo do tempo.

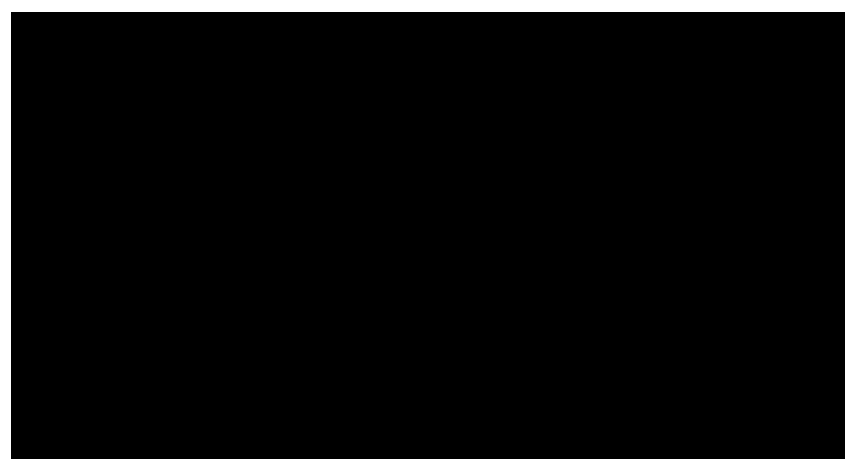

Fonte: Autores

Considerando a evolução entre 1984 e 2008 observa-se que algumas classes apresentam pouco crescimento ou nenhuma variação, como: Uso Múltiplo (crescimento de 1\%), 
Área Urbana (crescimento de 0,01\%), Reflorestamento (crescimento de 0,18\%), Uso Indefinido (crescimento de 0,02); Massa d'água e Lagoa Cárstica (inalterado).

Não houve expansão significativa nas áreas com Uso Múltiplo, que caracterizam a agricultura de subsistência em pequenas propriedades com uso diversificado da terra, incluindo diversos tipos de culturas agrícolas permanentes e temporárias, além da pecuária. Esse tipo de uso é feito de maneira intensiva desde a década de 1970 (Brasil, 1976), ocupando principalmente as áreas próximas às drenagens. É um tipo de uso mais antigo e já consolidado, mostrando pouco crescimento desde 1984.

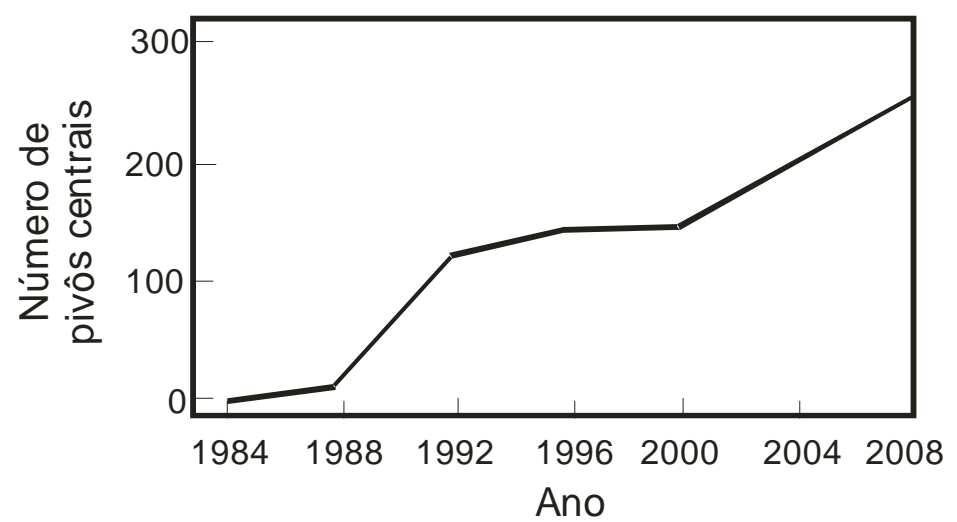

Gráfico 3-Número de pivôs centrais entre 1984 e 2008.

\section{CONCLUSÕES}

O sensor PRISM permitiu um detalhamento das principais classes de usos e cobertura do solo em 2008.0 uso da interpretação visual apesar de ser uma técnica morosa mostra-se de maior acurácia para a detecção de mudanças e variações no uso e cobertura do solo da série temporal compreendida entre 1984 e 2008, com imagens do sensor e Landsat TM.

Foi possível observar um declínio da Vegetação Natural e ascensão da Agricultura no período entre 1984 e 2008. Apesar da área coberta com vegetação natural ainda ser maior, a agricultura de sequeiro (soja, milho e algodão) se destaca como a principal atividade em expansão, avançando sobre as áreas de Vegetação Natural numa taxa de mais de $1 \%$ ao ano. Além disso, esta conversão apresentou um avanço partindo da parte 
Oeste para Leste, mostrando-se dependente da estrutura geomorfológica e pluviométrica.

\section{REFERÊNCIAS}

BATISTELLA, M.et al.Monitoramento daexpansão agropecuária na Região Oeste da Bahia.Campinas: Embrapa Monitoramento por Satélite, 2002. 39 p., il. (Documentos, 20).

BRANNSTROM, C. et. al.Land change in the Brazilian savanna (Cerrado), 1986-2002: comparative analysis and implications for land-use policy. Land Use Policy,v. 25, p. 579-595, 2008.

BRASIL, Ministério da Agricultura. Levantamento Exploratório - Reconhecimento de Solos da Margem Esquerda do Rio São Francisco, Estado da Bahia. Recife: EMBRAPA, Ministério da Agricultura e Ministério do Interior(Boletim Técnico n. 38, Série Recursos de Solo), 1976, 404 p.

COPPIN, P. et al. Review article digital change detection methods in ecosystem monitoring: a review. International Journal of Remote Sensing, v. 25, n. 9, p. 15651596, 2004.

DE BRUIN, S. Querying probabilistic land cover data using fuzzy set theory. International Journal of Geographical Information Sciences, v.14, n. 4, p.359-372, 2000.

FLORENZANO, T. G. Sensoriamento Remoto para Geomorfologia. In: Florenzano, T. G. (Org.). Geomorfologia: conceitos e tecnologias atuais. São Paulo: Oficina de Textos. 2008.p. 31-71.

GASPAR, M.T.P.; CAMPOS, J.E.G. O Sistema Aquífero Urucuia. Revista Brasileirade Geociências,Curitiba.v. 37, n. 4-suplemento, p. 216-226, 2007.

GASQUES, J. G.; VILLA VERDE, C. M. Novas fontes de recursos, propostas e experiências de financiamento rural. Revista de Economia e Sociologia Rural, Brasília.v. 34, n. 3 e 4, p. 39- 80, 1996.

GUIMARÃES, E.N. \& LEME, H.J.C. Caracterização histórica e configuração espacial da estrutura produtiva do Centro-Oeste. Textos NEPO,Campinas.n. 33, p. 25-65, 1997. 
IBGE - Instituto Brasileiro de Geografia e Estatística. Censo Agropecuário 1990 a2008. Disponível em:<www.ibge.gov.br.> Acesso em: 01 jan.2010.

IGARASHI, T. ALOS mission requirement and sensor specifications. Advances inSpace Research, v.28, n.1, p. 127-131, 2001.

KLINK, C.A.; MACHADO, R.B. Conservation of the Brazilian Cerrado. Conservation Biology,v. 19, n. 3, p. 707-713, 2005

MAS, J.F. Monitoring land-cover changes: a comparison of change detection techniques. InternationalJournalof Remote Sensing,v. 18, p. 711-725, 1999.

MAZZETO SILVA, C.E. Ordenamento Territorial no Cerrado Brasileiro: da fronteira monocultora a modelos baseados na sociodiversidade. Desenvolvimento e MeioAmbiente. Curitiba.n.19, p.89-109, 2009.

MENDONÇA, J.O. O potencial de crescimento da produção de grãos no Oeste da Bahia. Bahia Agríc., Salvador.v. 7, n. 2, p.38-46, 2006.

MENKE, A.B. et al. Análise das mudanças do uso agrícola da terra a partir de dados de sensoriamento remoto multitemporal no município de Luis Eduardo Magalhães (Bahia - Brasil). Sociedade\&Natureza,Uberlândia, v. 2, n. 3., p. 315-326, 2009.

MUNYATI, C. Wetland change detection on the KafueFlats, Zambia, by classification of a multitemporal remote sensing image dataset.International Journal of RemoteSensing,v. 21, n.9, p.1787-1806, 2000.

SANO, E.E.; PINHATI, F.S.C. Espaço rural do oeste baiano: identificação de áreas agrícolas sob sistema de plantio direto por meio de dados obtidos por câmera digital e satélite CBERS-2 CCD. Geografia, Rio Claro.v. 34, n. 1, p. 117-129, 2009.

SANO, E.E. et al. Mapeamento semidetalhado do uso da terra do Bioma Cerrado. Pesquisa Agropecuária Brasileira, Brasília.v. 43, p.153-156, 2008.

SANTOS, A.B. dos et al.Plano Ambiental para o Município de São Desidério Bahia. Programa Nacional de Capacitação de Gestores Ambientais. Bahia. 2008.

SANTOS, C.C.M. Os cerrados da Bahia sob a lógica do capital. Revista Ideas, Rio de Janeiro, v. 2, n.1, p. 76-108, 2008. 
SEI - SUPERINTENDÊNCIA DE ESTUDOS ECONÔMICOS E SOCIAIS DA BAHIA. Panorama da migração dos municípios baianos em1995-2000. Salvador: SEI, 2007. 259 p.

TADONO, T. et al. Calibration and Validation of PRISM Onboard ALOS. In: ISPRS Congress, 20., Istanbul, Turkey. The International Archives of Photogrammetry, Remote Sensing and SpatialInformation Sciences, v.35, part.B1, p. 13-18, 2004.

Artigo encaminhado para publicação em julho de 2012.

Artigo aceito para publicação em outubro de 2012. 